\title{
Perceived self-image in adolescent idiopathic scoliosis: an integrative review of the literature*
}

\author{
IMAGEM PERCEBIDA NA ESCOLIOSE IDIOPÁTICA DO ADOLESCENTE. REVISÃO DA \\ LITERATURA
}

\author{
IMAGEN PERCIBIDA EN LA ESCOLIOSIS IDIOPÁTICA ADOLESCENTE: REVISIÓN \\ INTEGRATIVA DE LA LITERATURA
}

\section{Maria Isabel Bonilla Carrascoํ, Maria Carmen Solano Ruiz²}

\begin{abstract}
Objective: To learn about the experiences of adolescents diagnosed with idiopathic scoliosis. Method: Integrative review of the literature published within a specified time frame. Results: For both sexes, the predominant clinical symptom of this condition appears to be the negative effect that the deformity exerts on perceived self-image. Quantitative studies used numerical scores to assess perceptions of body image but did not analyse emotional aspects. Patients treated surgically were found to have a better self-image than patients treated with a brace. Quality of life was improved by a reduction in the magnitude of the curve. Conclusion: Spinal deformity exerts a psychological effect on adolescent girls.
\end{abstract}

\section{DESCRIPTORS}

Scoliosis

Adolescent

Body image

Self concept

Emotions

Review

\section{RESUMO}

Objetivo: Conhecer as experiências vividas por adolescentes com diagnóstico de escoliose idiopática. Método: Revisão integrativa da literatura, estabelecendo limites no ano de publicação dos documentos. Resultados: Para ambos os sexos, o efeito negativo da deformidade na percepção da própria imagem é o sintoma clínico predominante; os estudos quantitativos apresentam uma classificação numérica para avaliar a percepção da imagem corporal, porém sem recolher os aspectos emocionais; a autoimagem é melhor em pacientes tratados cirurgicamente e pior em pacientes tratados com cinta e a diminuição da magnitude da curva proporciona uma melhor qualidade de vida. Conclusão: A deformidade da coluna vertebral afeta psicologicamente os adolescentes.

\section{DESCRITORES \\ Escoliose \\ Adolescente \\ Imagem corporal \\ Autoimagem \\ Emoções \\ Revisão}

\section{RESUMEN}

Objetivo: Conocer las experiencias vividas por adolescentes diagnosticados con escoliosis idiopática. Método: Revisión integrativa de la literatura, estableciendo los límites de búsqueda en el año de publicación de los documentos. Resultados: El síntoma clínico predominante para ambos sexos es el efecto negativo de la deformidad en la percepción de la propia imagen; los estudios cuantitativos presentan una clasificación numérica para evaluar la percepción de la imagen corporal sin recoger los aspectos emocionales; la autoimagen es mejor en pacientes tratados quirúrgicamente y peor en pacientes tratados con corsé y la disminución de la magnitud de la curva proporciona una mejor calidad de vida. Conclusión: La deformidad de columna vertebral afecta psicológicamente a los adolescentes.

\section{DESCRIPTORES \\ Escoliosis \\ Adolescente \\ Imagen corporal \\ Autoimagen \\ Emociones \\ Revisión}

\footnotetext{
*Extracted from the thesis "Percepciones de las mujeres jóvenes frente a la escoliosis", University of Alicante, $2014 .{ }^{1}$ Lecturer, Autonomous University of Barcelona, Barcelona, Spain. ${ }^{2}$ Vice-Dean of Academic Affairs [Nursing], Faculty of Health Sciences, University of Alicante, Alicante, Spain.

Rev Esc Enferm USP
2014; 48(4):748-57
www.ee.usp.br/reeusp/ $\quad \begin{array}{ll}\text { Received: } 04 / 12 / 2013 & \text { Approved: } 05 / 21 / 2014\end{array}$
}




\section{INTRODUCTION}

The natural history of scoliosis is variable and depends on the pathogenesis in question and the type of curvature ${ }^{(1)}$. Adolescent idiopathic scoliosis (AIS) may progress until causing pain, limiting physical function or mobility and negatively affecting mental self-image or psychological function, thereby causing health problems that affect the development of friendships and the ability to adapt socially ${ }^{(2-4)}$.

AIS affects healthy patients in puberty. The diagnosis is made by exclusion, and is only reached when other causes of scoliosis, such as vertebral malformations and neuromuscular diseases and syndromes, have been ruled out. The severity of scoliosis is determined from the Cobb angle, visualised in an anterior-posterior x-ray, and this is probably the most decisive factor when determining the treatment strategy. However, appearance can also influence the decision to opt for surgical treatment ${ }^{(1,5-6)}$ : the majority of patients are concerned about their body before, during and after treatment, although to a varying extent depending on the individual, and this anxiety may affect their general well-being(7).

As with any disease, the aim of AIS treatment is to alter the course of the disease's natural history, and it is thus necessary to conduct long-term studies of treatment outcomes. However, few long-term studies have been performed, rendering it difficult to assess the outcome of the treatments employed. Nevertheless, there is a growing interest in the validation of instruments that permit complete assessment of the disease, of patients' perceptions of the deformity, of the consequences of clinical decisions and of the effectiveness of the treatments employed ${ }^{(8)}$. These tools consist of questionnaires, and the results they yield are widely used to assess the clinical effectiveness of different orthopaedic and surgical treatments.

Recent clinical studies have provided evidence demonstrating the usefulness of these scales in therapeutic evaluations $^{(9)}$. At present, treatment outcomes as regards aesthetics are usually measured in terms of significant changes and/or improvements in vertebral rotation after treatment with a brace, a reduction in the Cobb angle after surgery, or improved perception of the deformity as evaluated through a questionnaire ${ }^{(10)}$.

Most studies have tended to emphasise the physiological assessment of parameters when evaluating the therapeutic effect of a treatment ${ }^{(3)}$. However, the true measure of outcomes is whether patients go on to develop the problems that the surgery was originally designed to prevent.

A better understanding of adolescents' body perceptions can contribute to improving the care provided. It is possible to identify the emotions and feelings that the deformity arouses and its effect on mental health and quality of life. Thus, the outcomes of current treatments could be improved by identifying the emotions and feelings that this deformity induces in young people with AIS and by providing therapeutic nursing communication based on tools such as active listening, feedback and empathy, obtaining essential information about the state of mind of the young people suffering this deformity.

The objective of this study was to collate the reported perceptions, experiences and needs of adolescent girls diagnosed with idiopathic scoliosis.

\section{METHOD}

An integrative review of the literature contributes to extending our knowledge of the scoliotic deformity and to gaining a better understanding of this phenomenon, in the light of previous studies. It also enables the generation of new perspectives which help identify any lacunae in our knowledge of the subject under study, and permits a synthesis of published studies in order to draw general conclusions. The fundamental aim of this review was to extract the conclusions reached in previous studies and summarise them in order to formulate conclusions about body perception in AIS.

To this end, we conducted a search for scientific articles in the following databases: PubMed, Web of Knowledge, SCOPUS, SciELO, Cuiden and Cuidatge. The search was performed between May 2011 and January 2012. We identified a total of 122 articles and decided to limit the search by date of publication, considering only those articles published in the last 6 years. As a result, our initial total was reduced to 74 articles. Of these, and working independently, we rejected any study that did not meet the inclusion criteria. We also searched the bibliographic references given in the articles that were not rejected in order to identify further studies that could be included in our review. When we combined our results, our final selection included a total of 52 studies.

Inclusion criteria: articles reporting studies on body perception in adolescent idiopathic scoliosis.

Exclusion criteria: articles about adolescent idiopathic scoliosis which did not address body perception, and articles reporting studies on subjects aged less than 12 or more than 24 years old.

The keywords used in the searches were:idiopathic scoliosis adolescent self perception, idiopathic scoliosis adolescent body image, escoliosis idiopática adolescente imagen corporal, escoliosis idiopática adolescente percepción corporal, escoliosis.

A computer file with folders was created in order to organise and evaluate the selected articles. The most relevant contributions of the studies were summarised by labelling those aspects that dealt with body perception, mental health, emotions and feelings, quality of life and deformity. Thus, the data were organised according to similarities and differences, yielding a finding that was analysed and interpreted. 


\section{RESULTS}

In most of the studies, patients under 10 years old and over the age of 18 were excluded from the samples on the grounds that their attitude towards scoliosis could differ, especially in terms of the adverse psychological effects and social impact of body image compared to the perspective of adolescents ${ }^{(9)}$. Subjects aged 10 to 15 years old are at a critical stage as regards the development of self-concept, and with scoliosis as a constant reminder of their body, they realise that their own is not as perfect as those of their friends. These patients tend to have a negative self-concept, feel anxiety because they are different and may even experience a sense of guilt and shame about their condition ${ }^{(11)}$.

The most frequently used approach in the studies was to administer a single questionnaire measuring depression, back pain, limitations on physical capacity and negative self-perception of the body, in order to determine the reduction in quality of life of patients with idiopathic scoliosis $^{(12)}$. In general, the studies employed a quantitative approach to assess these dimensions.

\section{Treatments employed in scoliosis}

As with any disease, the aim of AIS treatment is to alter the course of the disease's natural history, and it is thus necessary to conduct long-term studies of the outcomes of these treatments in order to assess the evolution of the disease or deformity. However, few long-term studies have been performed, rendering it difficult to assess the outcome of the treatments employed; nevertheless, there is a growing interest in the validation of measures that would permit complete assessment of the disease, of patients' perceptions of the deformity, of the consequences of clinical decisions and of the effectiveness of the treatments employed ${ }^{(8)}$. Most studies have tended to emphasise the physiological assessment of parameters when evaluating the therapeutic effect of the treatment ${ }^{(3)}$.

Two clear treatment strategies were observed in all the studies analysed: surgical treatment and conservative treatment.

Surgical treatment is an effective method of improving aesthetic deformity by mitigating the Cobb angle, but does not in itself eliminate rib deformity (hump), which can worsen after spinal fusion, and surgeons may need to consider rib resection (costoplasty) to improve the aesthetic appearance ${ }^{(13-14)}$. The goals of surgical treatment have changed over time, and these days expectations are more modest. Surgery is now considered a preventive measure to halt progression, improve acceptability of self-image and reduce curvature ${ }^{(14-15)}$, although its role in the prevention of other negative effects in the long-term remains unclear ${ }^{(16)}$. Corrective surgery in the adolescent population may have a limited impact on the patient's self-image, mental health and satisfaction due to the role played by physiological, sociocultural and biopsychosocial factors $^{(17)}$. Surgical intervention may also have an adverse effect on variables such as physical function and mobility, and consequently on quality of life, due a reduction in flexibility of the spine and the possible discomfort that this can entail. Thus, patients treated surgically may experience a change in their quality of life, which will be affected both by the reduction in the deformity and the loss of movement associated with such surgery ${ }^{(12,18)}$. Changes in self-image prior to surgery can also have an important influence on surgical outcomes, since surgery entails the appearance of visible postoperative scars ${ }^{(19)}$.

Meanwhile, the main objective of conservative treatment is to prevent progression of the curvature, and thus alleviate pain and improve aesthetic perception and lung function. The extent to which all these factors (perception, function and pain) influence the patient's capacity will affect their physical, emotional and social well-being, and an interrelation between them is necessary for good psychosocial functioning and successful treatment ${ }^{(18.20)}$. Some authors have claimed that there is little evidence to support conservative treatments such as physiotherapy, and they question their efficacy in the treatment of patients with scoliosis. More evidence exists as regards the use of orthopaedic braces as a means to halt the progression of the curvature ${ }^{(21)}$, although this implies observation of the impact of the brace on self-image. In this case, the adolescent's body is the main contributing factor to stress ${ }^{(20,22)}$.

\section{Measurement instruments: questionnaires}

Several methods have been used to measure subjective perceptions of the magnitude of the deformity. One approach is to elicit the patient's personal impression of his or her deformity ${ }^{(23)}$. Patients are told that the questionnaires have been designed to inform doctors on how patients perceive their body in relation to the curvature of the back. Some of these instruments measure quality of life, such as the Quality of Life Profile in Spinal Deformities (CAVIDRA) and the SRS-22 (Scoliosis Research Society) questionnaire, which uses scales to determine self-perceived body image ${ }^{(24)}$.

Over the last ten years, surgeons have made increasing use of the SRS questionnaire, which is specifically designed to compare postoperative changes in patients with scoliosis $^{(13)}$, and it has become the tool of choice for measuring outcomes in patients with idiopathic scoliosis. It has been shown to be reliable and valid with adolescents and adults. The instrument uses domains to assess patients' physical function, pain, self-image, mental health and satisfaction/dissatisfaction with management, and also yields a total score. The total score is calculated from the average of each of the domain scores. This has the advantage of providing a total score, but also means that the individual domains must be taken into account when interpreting the results ${ }^{(25)}$. However, the lack of any previous instrument raises questions about validation of the
Perceived self-image in adolescent idiopathic scoliosis: an integrative review of the literature Carrascro MIB, Ruiz MCS 
SRS, and renders interpretation and comparison of studies difficult $^{(13)}$. Nevertheless, as result of its anthropometric properties, its use has been proposed in English-speaking countries and, more recently, it has been culturally translated and validated in other languages (e.g. Spanish, Turkish, Dutch, Japanese, Chinese and German) ${ }^{(26)}$, consolidating and confirming its factorial structure, reliability and validity. Thus it is now possible to compare quality of life related to the health, and in particular to the functional state, of adolescent patients with idiopathic scoliosis ${ }^{(8,26)}$.

Despite the relatively recent introduction of the SRS22 questionnaire, it is widely used because it is the only instrument specifically designed to evaluate quality of life in idiopathic scoliosis. Other questionnaires take into account that the notion on which a questionnaire is based is that the perception of appearance is a unique feature of scoliosis and that specific visual instruments such as, for example, the Walter Reed Visual Assessment Scale (WRVAS) perform better at assessing this aspect than other types of instrument ${ }^{(9)}$.

Another questionnaire on the appearance of the spine, developed to assess the self-perceptions of patients with AIS, is the Spinal Appearance Questionnaire (SAQ). Some studies have attempted to compare the results of the SAQ questionnaire by assessing parents' perceptions of their child's deformity and comparing the results with scoliosis patients' self-perceived body image. In this case, the questionnaire contained 19 questions to be answered by the patient and 20 to be answered by the parents ${ }^{(27)}$. In other comparisons, some studies have used and compared tools such as the SAQ and the WRVAS. The SAQ emerged as a development of the WRVAS to measure patients' and their parents' perceptions of various aspects of the appearance of the spinal deformity. It includes additional drawings, more questions about the uniform appearance of the breasts, chest, waist, length of the limbs and shoulders, and general items related to appearance, self-image and postoperative scarring. The instrument uses standardised drawings showing different degrees of severity of the components of the spinal deformity, and additional questions about the degree of dissatisfaction with other aspects of the appearance of the deformity ${ }^{(28)}$.

Also of note is the Piers-Harris Children's Self-Concept Scale (PHCSS), which measures adolescents' emotions and behaviour, applied to subjects with AIS. This questionnaire contains 80 yes/no questions divided into six subscales: behavioural adjustment, intellectual and school status, physical appearance and attributes, freedom from anxiety, popularity, and happiness and satisfaction. A yes response obtains a score of 1 point, and a no response, 0 points. A high score is positive, thus a high total score indicates that the subject has a high self-concept ${ }^{(11)}$.

Another notable questionnaire is the Brace Questionnaire (BRQ), which was developed to assess quality of life in adolescents with scoliosis who receive conservative treatment with an orthopaedic brace. This questionnaire measures the effect of conservative treatment on patients with AIS. The BRQ questions are grouped into eight specific areas: general health perception, physical functioning, emotional functioning, self-esteem and aesthetics, vitality, school activity, body pain and social functioning. The items were formulated so that they could be meaningfully answered with the following five response categories: always, most of the time, sometimes, almost never and never. The minimum score is theoretically 20 and the maximum is 100, where a higher score indicates a better quality of life ${ }^{(22)}$.

The psychological stress that may be induced by deformity in patients with scoliosis treated with a brace can also be measured through a questionnaire; the BSSQ (Bad Sobernheim Stress Questionnaire). This questionnaire contains eight questions and the response to each is scored from 0 for highest stress to 3 for lowest stress. The maximum score is 24 , and a higher score indicates less stress ${ }^{(29)}$.

Other questionnaires identified in this review were the TAPS (Trunk Appearance Perception Scale) ${ }^{(30)}$, the CAVIDRA profile and the QLPSD (Quality of Life Profile for Spine Deformities) ${ }^{(31)}$. It should be noted that some authors considered questionnaires such as the short form ${ }^{(36)}$ health survey (SF-36) and the SRS-22 to have a poor self-image parameter; however, questionnaires such as the SAQ with its visual depictions could provide better assessment measures in the future ${ }^{(32)}$.

\section{Body perception through questionnaires}

Most assessment scales administered to patients with spinal deformity include a self-image domain. However, people's perspectives may change over the course of their lives, rendering this a very difficult parameter to assess. Nevertheless, self-image is one of the most important characteristics related to spinal deformity ${ }^{(9)}$. Measurement of selfimage, or how someone perceives their own appearance, is a process in constant evolution. Self-image scores have a high correlation coefficient with correction of the deformity of the curve, but it is not possible to determine from these data whether pronounced curves are more correlated or whether these patients are more sensitive about their body shape due to greater deformity. Interestingly, several authors have failed to find a correlation between SRS body image scores and magnitude of the postoperative curve ${ }^{(25)}$.

Among the questionnaires that assess body perception, the most widely used instrument is the SRS-22. According to some authors, this offers good metric properties but could be improved by adding some of the dimensions from the CAVIDRA questionnaire and the perceived body image dimension from the TAPS questionnaire ${ }^{(31)}$. Other authors, however, consider that there is no relationship between the SRS-22 and categories of deformity, suggesting that the relationship between the deformity and perceived body image, pain and function is insignificant ${ }^{(23)}$. Similarly, in some studies, the domain of self-image presented a moderate 
capacity to discriminate between subjects belonging to the different categories of curvature severity being compared, to which doctors often recommend different types of treatments. It has been shown that the strength of the correlation between SRS-22 domains and severity of the curve was similar to that reported for other non-surgical subjects and in mixed samples with and without surgery. These results suggest that the SRS-22 cannot detect differences between people with different degrees of severity of the curve, or between those receiving conservative treatment $^{(4)}$. In contrast, other studies have established that the SRS-22 questionnaire has the capacity to discriminate between two groups on the basis of the magnitude of the curve. The difference in scores for its domains (better quality of life with less deformity) is most evident in the domain of self-image. In these studies, it has been observed that patients with spinal fusion do not report increased pain or diminished perceptions of body image, nor do they report reduced physical function in general compared to nontreated patients with similar degrees of deformity. However, what has been observed in patients with surgical fusion is a statistically significant reduction in the score for the domain of activity, as well as in the total SRS score. Thus, one can conclude that the overall effect of surgical correction is positive and that the patient's quality of life depends on the individual effects of spinal fusion and reduction of the deformity, which exerts a considerable influence on aesthetics. Although spinal fusion entails a reduction in patients' activity, and this in turn has a negative effect on quality of life, a reduction in the magnitude of the curve constitutes a positive aesthetic improvement which affects all areas and ultimately leads to a better quality of life for patients after treatment ${ }^{(12)}$. The domain appearance thus becomes the most obvious effect of surgery, and considerably improves the final results of the SRS questionnaire. A 2-year followup showed insignificant correlations ${ }^{(17)}$. For some authors, the improvement in clinical and functional outcomes measured using the SRS-22 after surgery involving costoplasty associated with instrumented posterior spinal fusion, is very significant, especially in the domain of self-image. Surgery appears to obtain a significant correction of the rib hump and consequently, an improvement in the patient's self-image ${ }^{(14,33-34)}$. Surgeons regard aesthetic appearance as grounds for surgical intervention, and rib resection (costoplasty) is increasingly being used for this purpose ${ }^{(13)}$. Surgery improves all the categories compared; all the domains presented significant differences after surgery, and concern about appearance was higher in patients than in their parents, in both cases diminishing notably after surgery. Also worthy of mention is the percentage of concern about the surgical scar one year after surgery ${ }^{(28)}$.

Thus, the highest scores for self-image were obtained by patients treated surgically and the lowest by patients treated with a brace. Among patients under observation, the score for self-image was lower the greater the angle of the curve. In this study, the self-image score among patients treated with a brace did not differ significantly when the magnitude of the angle of the curve was higher than $40^{\circ}$, This result requires an explanation, as the location of the curve has a significant relationship with the self-image score ${ }^{(9)}$.

In general, correction of the deformity was perceived by patients as an improvement in scores for domains such as pain and self-image ${ }^{(35-37)}$.

Regarding satisfaction with the outcomes achieved in the management of their deformity, some patients felt they had received the best treatment possible for their condition, although they were not completely satisfied with the aesthetic results obtained ${ }^{(38)}$.

\section{Scoliosis, self-image, emotional disturbances and mental health}

Traditionally, the aesthetic sequelae have been considered a critical factor for patients with idiopathic scoliosis. The psychological distress experienced by these patients is often attributed to the development of trunk deformity. The questions posed about this highlight the idea that these patients regularly suffer psychological conflicts, and when these conflicts appear, they are due to the cosmetic effect ${ }^{(12,23,29)}$.

Patients and their families are often very concerned about the effect on the patient's image of the hump (rib), which may also cause pain and functional limitation of the rib cage, and this anxiety about aesthetics is also an important factor related to self-esteem. The low level of satisfaction with life and the declining self-esteem often associated with physical disorders can have a serious emotional and psychological impact which leads to deterioration in physical condition and self-perceived quality of life ${ }^{(3,14,39)}$.

In sum, AIS may cause psychosocial problems due to its potentially adverse effects on body image. Conservative treatments such as the use of a brace can also exacerbate this problem. The psychological impact of brace treatment procedures has been quantified using various questionnaires $^{(29,40-42)}$, and it has been found that patients with AIS show a greater propensity to develop feelings of dissatisfaction regarding the appearance of their body. These people tend to worry that their organs will become increasingly different than normal. As a result, patients with AIS tend to lack self-confidence and have a sense of inferiority and even shame. This is a disturbing experience that forces patients to cope with stress, denial, fear, anger and shame. This lack of self-confidence can lead to a growing sense of pessimism and anxiety, resulting in a deterioration in social functioning and total psychological isolation; therefore, patients may require social as well as physical rehabilitation ${ }^{(3,41-42)}$. The lack of support from specialised professionals when receiving the bad news of the need to wear a brace, as well as the minimal emotional support provided, mainly by the orthotists and doctors during follow-up visits, engender a situation of stress ${ }^{(41)}$.
Perceived self-image in adolescent idiopathic scoliosis: an integrative review of the literature Carrascro MIB, Ruiz MCS 
All this symptomatology influences patients' quality of life, affecting them at a physical, psychological and social level. In the case of scoliosis, the most important dimensions quantified are pain, body image, mobility, sleep disorders and a combination of factors related to functionality in general ${ }^{(22,31)}$.

As regards mental health, some studies have suggested that the correlation between self-concept and mental health indicates that individuals with low self-esteem have more mental health problems than people with a better self-concept ${ }^{(11)}$.

The SRS-22 scale is generally used to assess patient satisfaction with the treatment received, but this scale does not permit a broad assessment of mental health and has very few items related to self-esteem and satisfaction with life. No study has specifically evaluated changes in satisfaction with life and self-esteem in patients with AIS following treatment using tests specifically designed to measure these parameters ${ }^{(3)}$. Some studies have concluded that selfimage and scores for the subscale of mental health vary according to the treatment received, reporting that the lowest scores for the domain of self-image were obtained by patients who had received physical therapy, whilst the lowest scores for mental health were obtained by postoperative patients ${ }^{(9)}$.

The authors concluded that although conservative treatment is medically appropriate in the case of the least severe curves, it has a consistently negative effect on mental health. The lack of attention paid to patients' mental health in general could be the cause of the reduction in self-esteem observed in patients with less severe curves ${ }^{(3)}$.

Untreated AIS and its potential consequences, such as back pain, restricted pulmonary function and deformity, affect both function and self-esteem. However, few studies or publications have addressed this issue. Some studies have shown that certain patients perceive themselves to have worse health and restricted physical and social activity ${ }^{(5)}$. Studies of older patients with untreated AIS have reported that these are less satisfied than control cases with their body image, and one third of the patients reported that the deformity restricted their lifestyle. As patients grow, many of them may experience back pain and disorders of a cosmetic nature. Other studies have failed to find a significant difference between the population with AIS and control cases when comparing their capacity to perform activities of daily living ${ }^{(5)}$. It should be noted that adolescence is widely accepted to be difficult period psychologically in its own right, and when this is complicated by the biopsychosocial effects of scoliosis and treatment with braces, a situation of extreme stress can result ${ }^{(41)}$.

\section{Self-image in men and women}

In some studies, the SRS-22 questionnaire has been adapted and transformed into the SRS-30 in order to assess postoperative differences between the two sexes. It was found that preoperatively, men had a better selfimage than women, and in a two-year follow-up, selfimage scores had improved significantly for both sexes without being significantly different. In short, men are less affected than women in terms of perceived selfimage/appearance prior to surgery. For both sexes, the predominant clinical symptom of AIS appears to be the negative effect that the spinal deformity exerts on perceived self-image and appearance, since this domain obtains the least favourable of all domain scores for both sexes prior to surgery. Men also obtained better scores for the mental health domain prior to surgery. However, both men and women showed a similar improvement in mental health scores after surgery ${ }^{(43)}$.

Conversely, observational studies using the Piers-Harris questionnaire did not find significant differences between the sexes as regards self-image ${ }^{(37)}$.

\section{DISCUSSION}

In terms of the treatment of scoliosis, the studies analysed concluded that surgical intervention can be expected to produce excellent results, unless significant complications arise ${ }^{(14,25)}$. When patients decide to undergo surgery, they weigh up the risks of surgery against their families' perception of their deformity and the possibility that this deformity will progress in the future ${ }^{(44)}$. Thus for some authors, surgeons consider aesthetic appearance as grounds for surgery, and rib resection (costoplasty) is becoming an increasingly frequent treatment strategy.

Nevertheless, it should be noted that the surgeons' assessment of the cosmetic outcome of an operation does not coincide with that of the patients themselves. Research on surgical treatment has highlighted the crucial need to inform all patients and relatives of the objectives and expectations of surgery, and has stressed that these objectives and expectations must coincide with the patients' own needs ${ }^{(13)}$.

In terms of conservative treatment, studies have found that modern braces have a clear impact on the patient's clinical appearance. Clinical improvement usually involves an improvement in the Cobb angle, and this can be achieved with braces when the curve is less than $45^{\circ}$, and also sometimes in cases of curves of greater magnitude. It is well known that compliance is fundamental to the outcome of treatment using a brace, and that there are ways to improve such compliance. One way to do this could be to reduce the size, in other words: to make smaller braces. It is assumed that when patients experience less stress, compliance improves, but this is an unproven assumption and it is not possible to give sufficient data about length of time the brace is used ${ }^{(28)}$.

In general, all adolescents present problems of adaptation to the type of treatment proposed, and the period of 
treatment is usually characterised by negative emotional states such as sleep disturbances, increased irritability, denial, anxiety, fear and mood swings. However, involving a psychologist in the management of these emotional responses could lead to an improvement in the quality of the treatment ${ }^{(45)}$. Two aspects should be taken into account; on the one hand, adolescents with low self-esteem may experience mental health problems such as depression or anxiety, and these problems will inevitably lead to increased difficulty in coping with life. Meanwhile, negative experiences such as wearing a brace can induce anxiety, feeling lonely and despised, and guilt. As a rule, all these emotions hinder the development of self-concept ${ }^{(11,41-42)}$.

Attempts to determine the perceived self-image of adolescents with idiopathic scoliosis have involved trying to assign a numerical score to the constituent elements of a questionnaire in order to assess a dimension that is subjective, in a state of constant flux, susceptible to external influences and difficult to quantify. A wide range of questionnaires have been used and the domains that characterise them are varied. In this attempt to accurately define the body perceptions of these patients, comparisons have been conducted of the results obtained using different types of questionnaire, and adaptations have been made of the SRS-22, which is the most widely used questionnaire to date. One example of this is the SRS-24, an adaptation of the SRS-22 which reflects differences between two cultures (American and Japanese). Japanese patients report less back pain, a negative self-image in relation to the spinal deformity, and better function and daily activity than American patients. The cultural differences between the USA and Japan, such as a modest or reserved personality, could affect results, especially in the field of self-image. It is probable that patient perceptions will differ according to cultural differences and ethnicity ${ }^{(26,46)}$. We therefore propose the use of a qualitative approach in future studies of perceived body image in idiopathic scoliosis, since qualitative studies take the cultural context into account, include open questions that facilitate the expression of feelings and emotions, and allow subjects to express their body perceptions in their own words without having to adjust their responses to a visual model or a single response option in a closed question. The use of qualitative study methods might help render the treatment of AIS more multidisciplinary and facilitate consideration of the psychosocial factors that arise from those feelings and emotions.

As regards comparisons of different studies, some have compared the results obtained using the SF-36 with those yielded by the WRVAS ${ }^{(9)}$. Others have compared the SRS-22 with the WRVAS and concluded that the two scales are not mutually exclusive but complementary, and that the use of both in conjunction would provide a better assessment of body perception, since they each compensate for the other's respective omissions ${ }^{(23)}$. The SAQ and SRS have also been compared, leading to the conclusion that there is an considerable ceiling effect for the domain of future expectations since the desire to achieve a perfect self-image in the future is characteristic of the majority of the adolescents ${ }^{(24)}$.

Trunk deformity can be perceived differently by children and parents ${ }^{(27)}$. Some authors have reported that the SRS-22 questionnaire reveals a significant difference in the patients' perception of the deformity which is influenced by their parents' perception according to the TAPS questionnaire ${ }^{(47)}$. From a methodological perspective, the ideal would be that the patient's perception and the clinical and radiological findings were highly correlated measures of the deformity. In everyday practice, however, it is common to find discrepancies between the radiological deformity (Cobb angle) and the aesthetic deformity. It is crucial to be aware of the patient's perspective since this determines the decision to operate, and the TAPS questionnaire appears to be a valid tool to assess this perception ${ }^{(30)}$.

As mentioned above, the most widely used instrument is the SRS-22, which has good metric properties but which could be improved by adding some of the dimensions from the CAVIDRA questionnaire and a perceived body image dimension (TAPS) ${ }^{(31)}$.

Lastly, the results of questionnaires such as the BSSQ can be employed to measure the coping strategies that patients use and the deterioration that patients experience when wearing a brace ${ }^{(29,48)}$. One study concluded that there were no ceiling or floor effects, and that the total score could distinguish between patients with mild and moderate scoliosis. The results indicated that patients with moderate scoliosis obtained lower global scores on the BRQ, thus suggesting poorer quality of life $\mathrm{e}^{(22)}$.

\section{CONCLUSION}

Self-image is the most difficult domain of spinal deformity to measure, especially because people's perspectives may change over the course of their lives. This parameter is therefore difficult to assess, although self-image itself is one of the most important characteristics related to spinal deformity. The measurement of self-image is a constantly evolving process contingent upon a person's level of maturity and their sociocultural environment.

However, the cultural context is the only aspect taken into account when using a quantitative assessment questionnaire, which is translated and adapted to the particular culture in which it will be administered. The most frequently used and widely adapted questionnaire is the SRS-22.

Patients treated surgically obtain the highest scores for self-image, whilst the lowest scores are obtained by patients treated with a brace. Patients under observation obtain a lower score for self-image the greater the angle
Perceived self-image in adolescent idiopathic scoliosis: an integrative review of the literature Carrascro MIB, Ruiz MCS 
of the curve; thus, although conservative treatment is medically appropriate for less severe curves, it nevertheless has a negative effect on mental health.

The overall effect of surgical correction was found to be positive in most of the studies, although the patient's quality of life depended on the individual effects of spinal fusion and a reduction of the deformity. A reduction in the magnitude of the curve constitutes a positive aesthetic

\section{REFERENCES}

1. Álvarez Garcia de Quesada LI, Núñez Giralda A. Escoliosis idiopática. Rev Pediatr Aten Primaria. 2011;13(49):135-46.

2. Parent EC, Dang R, Hill D, Mahood J, Moreau M, Raso J, et al. Score distribution of the Scoliosis Research Society-22 Questionnaire in subgroups of patients of all ages with idiopathic scoliosis. Spine. 2010;35(5):568-77.

3. Zhang J, He D, Gao J, Yu X, Sun H, Chen Z, et al. Changes in life satisfaction and self-esteem in patients with adolescent idiopathic scoliosis with and without surgical intervention. Spine. 2011;36(9):741-5.

4. Parent EC, Hill D, Mahood J, Moreau M, Raso J, Lou E. Discriminative and predictive validity of the Scoliosis Research Society-22 Questionnaire in management and curve-severity subgroups of adolescents with idiopathic scoliosis. Spine. 2009;34(22):2450-7.

5. Montalvo Galindo M, León Parra M. Escoliosis idiopática del adolescente. Rev Mex Ortop Pediátr. 2010;12(1):6-14.

6. Donaldson S, Hedden D, Stephens D, Alman B, Howard A, Narayanan $U$, et al. Surgeon reliability in rating physical deformity in adolescent idiopathic scoliosis. Spine. 2007;32(3):363-7.

7. Danielsson A, Hasserius R, Ohlin A, Nachemson A. Body appearance and quality of life in adult patients with adolescent idiopathic scoliosis treated with a brace or under observation alone during adolescence. Spine. 2012;37(9):755-62.

8. Monticone M, Baiardi P, Calabro D, Calabro F, Foti C. Development of the Italian Version of the revised Scoliosis Research Society-22 Patient Questionnaire, SRS-22r-I cross-cultural adaptation, factor analysis, reliability, and validity. Spine. 2010; 35(24):E1412-7.

9. Hashimoto H, Sase T, Arai Y, Maruyama T, Isobe K, Shouno Y. Validation of a Japanese Version of the Scoliosis Research Society-22 Patient Questionnaire among idiopathic scoliosis patients in Japan. Spine 2007;32(4):E141-6.

10. Zaina F, Negrini S, Atanasio S. TRACE (Trunk Aesthetic Clinical Evaluation), a routine clinical tool to evaluate aesthetics in scoliosis patients; development from the Aesthetic Index (AI) and repeatability. Scoliosis. 2009;4:3. improvement which affects all areas and ultimately leads to a better quality of life for patients after treatment.

In general, the studies analysed did not report differences between men and women, although one of them found that men have a better preoperative self-image than women. For both sexes, the predominant clinical symptom of AIS appears to be the negative effect that the spinal deformity exerts on perceived self-image and appearance.

11. Zhang J, Wang D, Chen Z, Gao J, Yu X, Sun H, et al. Decrease of self-concept in adolescent patients with mild to moderate scoliosis after conservative treatment running head: Self-concept in adolescent scoliosis patients. Spine. 2011; 36(15):E1004-8.

12. Tsutsui S, Pawelek J, Bastrom T, Lenke L, Lowe T, Betz R, et al. Dissecting the Effects of spinal fusion and deformity magnitude on quality of life in patients with adolescent idiopathic scoliosis. Spine. 2009;34(18):E653-8.

13. Hawes MC, O'Brien JP. A century of spine surgery: what can patients expect? Disabil Rehabil. 2008;30(10):808-17.

14. Sánchez-Márquez JM, Fernández-Baillo N, García-Fernández A, Quintáns J, Pérez-Grueso FJ. Efecto de la costoplastia en la función pulmonar y la estética en pacientes con escoliosis idiopática del adolescente. Rev Esp Cir Ortop Traumatolol. 2010; 54(3):156-61.

15. Weiss HR. Adolescent Idiopathic Scoliosis (AIS): an indication for surgery?A systematic review of the literature. Disabil Rehabil. 2008;30(10):799-807.

16. Weinstein SL, Dolan LA, Cheng JC, Danielsson A, Morcuende JA. Adolescent idiopathic scoliosis. Lancet. 2008;371(9623):1527-37.

17. Carreon LY, Sanders JO, Diab M, Sturm PF, Sucato DJ. Patient satisfaction after surgical correction of adolescent idiopathic scoliosis. Spine. 2011;36(12):965-8.

18. Negrini SB, Grivas T, Kotwicki T, Maruyama T, Rigo M, Weiss HR. Why do we treat adolescent idiopathic scoliosis? What we want to obtain and to avoid for our patients. SOSORT 2005 Consensus paper. Scoliosis [Internet]. 2006 [cited 2014 Mar 17];1:4. Available from: http://www.ncbi.nlm.nih.gov/ pmc/articles/PMC1475888/

19. Sánchez-Soler JF, Ramírez Valencia M, Martínez J, Bagó J, Andreu L, Puig L. Impact of physical self-perception in surgical result of patients with adolescent idiopathic scoliosis. From the 8th International Conference on Conservative Management of Spinal Deformities and SOSORT 2011 Annual Meeting. Scoliosis [Internet]. 2012 [cited 2014 Mar 17];7 Suppl 1. Available from: http://www.ncbi.nlm.nih.gov/pmc/articles/PMC3305066/ 
20. Rivett L, Rothberg A, Stewart A, Berkowitz R. The relationship between quality of life and compliance to a brace protocol in adolescents with idiopathic scoliosis: a comparative study. BMC Musculoskelet Disord [Internet]. 2009 [cited 2014 Mar 17];10:5. Available from: http://www.ncbi.nlm. nih.gov/pmc/articles/PMC2635344/

21. Weiss HR. Spinal deformities rehabilitation-state of the art review. Scoliosis [Internet]. 2010 [cited 2014 Mar 17];5:28. Available from: http://www.ncbi.nlm.nih.gov/pmc/articles/ PMC3023759/

22. Vasiliadis E, Grivas TB, Gkoltsiou K. Development and preliminary validation of Brace Questionnaire (BrQ): a new instrument for measuring quality of life of brace treated scoliotics. Scoliosis [Internet]. 2006 [cited 2014 Mar 17];1:7. Available from: http://www.ncbi.nlm.nih.gov/pmc/articles/ PMC1481574/

23. Pineda S, Bago J, Gilperez C, Climent JM. Validity of the Walter Reed Visual Assessment Scale to measure subjective perception of spine deformity in patients with idiopathic scoliosis. Scoliosis [Internet]. 2006 [cited 2014 Mar 17];1:18. Available from: http://www.ncbi.nlm.nih.gov/pmc/articles/ PMC1654183/

24. Carreon LY, Sanders JO, Polly DW, Sucato DJ, Parent S, RoyBeaudry $M$, et al. Spinal Appearance Questionnaire: factor analysis, scoring, reliability and validity testing. Spine. 2011;36(18):E1240-4.

25. Sanders JO, Carreon LY, Sucato DJ, Sturm PF, Diab M; Spinal Deformity Study Group. Preoperative and perioperative factors effect on adolescent idiopathic scoliosis surgical outcomes. Spine. 2010;35(20):1867-71.

26. Morse LJ, Kawakami N, Lenke LG, Sucato DJ, Sanders JO, Diab M. Culture and ethnicity influence outcomes of the Scoliosis Research Society Instrument in adolescent idiopathic scoliosis. Spine. 2012;37(12):1072-6.

27. Roy-Beaudry $M$, Beauséjour $M$, Joncas J, Forcier $M$, Bekhiche $\mathrm{S}$, Labelle $\mathrm{H}$, et al. Validation and clinical relevance of a French-Canadian version of the Spinal Appearance Questionnaire in adolescent patients. Spine. 2011;36(9):746-51.

28. Sanders JO, Harrast JJ, Kuklo TR, Polly DW, Bridwell KH, Diab $M$, et al. The Spinal Appearance Questionnaire: results of reliability, validity, and responsiveness testing in patients with idiopathic scoliosis. Spine. 2007;32(24):2719-22.

29. Weiss HR, Werkmann M, Stephan C. Brace related stress in scoliosis patients: comparison of different concepts of bracing. Scoliosis [Internet]. 2007 [cited 2014 Mar 17];2:10. Available from: http://www.ncbi.nlm.nih.gov/pmc/articles/ PMC2000861/
30. Bago J, Sanchez-Raya J, Sanchez Perez-Grueso FJ, Climent JM. The Trunk Appearance Perception Scale (TAPS): a new tool to evaluate subjective impression of trunk deformity in patients with idiopathic scoliosis. Scoliosis [Internet]. 2010 [cited 2014 Mar 17];5:6. Available from: http://www.ncbi. nlm.nih.gov/pmc/articles/PMC2852387/

31. Climent JM, Cholbi Llobell F, Rodríguez Ruiz C, Mulet Perry S, Mendéjar Gómez F, Pradas Silvestre J. La medida de la salud en la escoliosis. Rehabilitación. 2009; 43(6):299-305.

32. Sue-Min Lai SM, Burton DC, Asher MA, Carlson BB. Converting the SRS-24, SRS-23, y SRS-22 to the SRS-22r: establishing conversion equations using regression modelling. Spine. 2011;36(23):E1525-33.

33. Cáceres E, Molina A, Llado A. Tratamiento quirúrgico de la escoliosis idiopática del adolescente. Rehabilitación. 2009;43(6):294-8.

34. González López JL, Riquelme García FJ, Soleto Martín A, Villa García J, Vázquez Estévez J. Papel de la costoplastia en la cirugía de la escoliosis. Cir Pediátr. 2006; 19(2):81-86.

35. Tsutomu A, Shohei M, Toshiaki K, Tetsuharu N, Takana $\mathrm{K}$, Kazuhisa T. Long-term clinical outcomes of surgery for adolescent idiopathic scoliosis 21 to 41 years later. Spine. 2012;37(5):402-5.

36. Carreon LY, Sanders JO, Diab M, Sucato DJ, Sturm PF, Glassman SD; Spinal Deformity Study. The minimun clinically important difference in Scoliosis Research Society-22 Appearance, Activity, and Pain domains after surgical correction of adolescent idiopathic scoliosis. Spine. 2010;35(23):2079-83.

37. Vecina Dormido R, Kesting Jiménez ASM, Martínez-Fuentes J, Moya-Faz FJ. Escoliosis idiopática y autoconcepto en el adolescente. Rev Fisioter (Guadalupe) 2009;8(2):27-36.

38. Cheung KMC, Senkoylu A, Alanay A, Genc Y, Lau S, Luk KD. Reliability and concurrent validity of the adapted Chinese Version of Scoliosis Research Society-22 (SRS-22) Questionnaire. Spine. 2007;32(10):1141-5.

39. Suk S, Kim JH, Kim SS, Lee JJ, Han YT. Thoracoplasty in thoracic adolescent idiopathic scoliosis. 2008;33(10):1061-7.

40. Alomar E, Castillo J, D’Agata E, Pérez-Testor C, Rigo M. Spanish validation of Bad Sobernheim Scoliosis Questionnaire for adolescents wearing braces. Scoliosis. 2009; 4(S2:P3).

41. Sapountzi-Krepia D, Psychogiou M, Peterson D, Zafiri V, lordanopoulou $E$, Michailidou $F$, et al. The experience of brace treatment in children/adolescents with scoliosis. Scoliosis [Internet]. 2006 [cited 2014 Mar 19];1:8. Available from: http://www.ncbi.nlm.nih.gov/pmc/articles/PMC1481575/ 
42. Aulisa AG, Guzzanti V, Perisano C, Marzetti E, Specchia A, Galli $M$, et al. Determination of quality of life in adolescents with idiopathic scoliosis subjected to conservative treatment. Scoliosis [Internet]. 2010 [cited 2014 Mar 19];5:21. Available from: http://www.ncbi.nlm.nih.gov/pmc/articles/ PMC2958155/

43. Roberts DW, Savage JW, Schwartz DG, Carreon LY, Sucato DJ, Sanders JO, et al. Male-female differences in Scoliosis Research Society: 30 scores in adolescent idiopathic scoliosis. Spine. 2010;36(1):E53-9.

44. MacCulloch R, Donaldson S, Nicholas D, Nyhof-Young J, Hetherington R, Lupea D, et al. Towards an understanding of the information and support needs of surgical adolescent idiopathic scoliosis patients: a qualitative analysis. Scoliosis [Internet]. 2009 [cited 2014 Mar 19];4:12. Available from: http://www.ncbi.nlm.nih.gov/pmc/articles/PMC2694769/

45. Levitskiy F, Yaroslavska N, Litvinova N, Ryhlevskiy E, Bebeshko $V$, Plyatsek $A$, et al. Psychological problems of patients with scoliosis who utilize the Cheneau's brace [abstract]. In: 5th International Conference on Conservative Management of Spinal Deformities. Scoliosis. 2009;4 Suppl 1:064.
46. Watanabe K, Lenke LG, Bridwell KH, Hasegawa K, Hirano $\mathrm{T}$, Endo $\mathrm{N}$, et al. Cross-cultural comparison of the Scoliosis Research Society Outcomes Instrument between American and Japanese Idiopathic Scoliosis Patients: are there differences? Spine. 2007;32(24):2711-4.

47. Rigo M, D'Agata E, Jelacic M. Trunk appearance perception scale (TAPS): discrepancy between scoliosis children and their parents influence the SRS-22 secore. Scoliosis [Internet]. 2012 [cited 2014 Mar 17];7 Suppl 1:03. Available from: http://www.ncbi.nlm.nih.gov/pmc/articles/PMC3304958/

48. Botens-Helmus C, Klein R, Stephan C. The reliability of the Bad Sobernheim Stress Questionnaire (BSSQbrace) in adolescents with scoliosis during brace treatment. Scoliosis [Internet]. 2006 [cited 2014 Mar 19];1:22. Available from: http://www.ncbi.nlm.nih.gov/pmc/articles/PMC1764899/ 